\title{
PRÁCTICAS Y PERCEPCIONES SOBRE EL MANEJO Y RECOLECCIÓN DE RESIDUOS DOMICILIARIOS EN EL BARRIO PUEBLO NUEVO DE LA CIUDAD DE LAS PIEDRAS (URUGUAY)
}

\author{
Sonia Gau Angelo ${ }^{1}$
}

\section{Introducción}

Este trabajo está basado en una investigación etnográfica que tuvo por objetivo indagar en las prácticas relacionadas con los residuos en el barrio, aspectos que tienen que ver con la gestión de los RSU (Residuos Sólidos Urbanos). También, y principalmente, en las percepciones que los distintos actores involucrados tienen acerca de dichas prácticas. Para dicha investigación, que abarcó desde setiembre de 2016 hasta setiembre de 2017, el trabajo de campo se realizó en el barrio Pueblo Nuevo de la ciudad de las Piedras, departamento de Canelones (Uruguay). Las técnicas que se aplicaron fueron la de entrevista, conversación y observación participante. Se realizaron entrevistas a distintos vecinos en forma aleatoria, las cuales permitieron obtener la información para el trabajo de investigación. A este respecto, Velasco y Díaz de Rada señalan:

Casi todo el trabajo de campo es un ejercicio de observación y entrevista (...) para poder así captar (...) los comportamientos y los pensamientos, las acciones y las normas, los hechos y las palabras, la realidad y el deseo. La observación y la entrevista son dos modos básicos de obtener información, o más bien de producirla (Velasco y Díaz de Rada, 2006: 33).

A través de conversaciones, se abrieron las puertas al mundo que se quiso investigar: el mundo de los residuos domiciliarios, desde la perspectiva de los clasificadores, de los hurgadores, de los vecinos y de los comerciantes del barrio. Entre caminar, ver, preguntar y escribir, en un movimiento entre otros, se desenvolvió esta etnografía. En las distintas entradas del trabajo de campo, las técnicas de entrevista y observación dieron como resultado un mayor acercamiento a los informantes. No obstante, siempre se tuvo presente que el investigador de su entorno debe tomar distancia (Velho, 2004).

\footnotetext{
${ }^{1}$ Universidad de la República, Uruguay. Email: angelosgau@gmail.com ORCID id: https://orcid.org/0000-0003-0906-6930
} 
El propósito fue investigar una cuestión fundamental de la realidad social actual como es el tema de los residuos. Luego de la instalación del sistema de contenedores, los habitantes comenzaron a apropiarse de los lugares públicos para colocar deshechos, dando lugar a microbasurales junto a ellos, modificando a la vez que contaminando ese espacio compartido. La investigación busca ahondar en las prácticas que generan estos microbasurales junto a los contenedores, buscando las respuestas a través del trabajo etnográfico, acercándose a los diferentes actores que integran el sistema de recolección de residuos urbanos.

En este trabajo, la descentración etnográfica permitió tomar conciencia de que es el actor social (y no el investigador) el que posee la clave de la resolución de los problemas. Como señala Tyler (1991):

La etnografía postmoderna prima el discurso sobre el texto, presenta el diálogo como oposición al monólogo; y pone un énfasis mayor en la cooperación natural con el sujeto sometido a estudio, situación que contrasta grandemente con ésa en la que el observador el investigador, pertrechado de ideología, se toma por transcendente observador científico. (Tyler, 1991: 188)

\section{El mundo de los residuos en el barrio}

Cuando salgo a la calle a tirar la bolsa de basura que genero en mi casa, al acercarme al contenedor que está a escasos veinte metros de donde vivo lo encuentro casi desbordado (señal de que los recolectores no pasaron en la noche), con restos de materiales de construcción, ramas de árboles y envases de plástico arrojados a su costado. La realidad de los residuos en el barrio Pueblo Nuevo se presenta aquí y ahora. Este es el aquí y ahora que es foco de interés de mi investigación, y me aproximo a esa realidad.

Esta realidad que vivo cotidianamente es un mundo intersubjetivo que comparto con otros y que es tan real para los otros como lo es para mí (Berger y Luckmann, 2001). Por otra parte, sé que los otros tienen de este mundo común una perspectiva que no es idéntica a la mía, y aquí llego al punto del sector de problematización de esta realidad de la vida cotidiana que busco conocer y entender: por qué mis vecinos se apropian del espacio junto al contenedor para depositar residuos y cuál es la percepción que tienen de ello.

Mi calle se abre al escenario de la observación para ser explorada con curiosidad atenta a lo que se revele sobre mi objeto de atención, en ese juego de establecer los primeros contactos, de buscar información, de posicionarme en mi rol de investigadora 
(llena de expectativa, además), ya que necesito un trabajo mental constante que me permita observar y abrirme a la extrañeza y a la reflexividad del trabajo etnográfico.

Al llegar al campo me enfrento con la problemática de cómo realizar ese involucramiento social con las personas que son mi objeto de estudio, el manejar la impresión, el establecer el rapport, la empatía con el otro. Como experiencia primeriza lo primero que hago es ver. Me dejo ver. Me hago pública. Así decido integrarme a quienes serán objeto de mi investigación.

Observé que el vecino de la esquina acomodaba, haciéndolo rodar con dificultad, el contenedor desde donde estaba situado hacia el lugar en el que siempre está. En ese espacio público quise construir mi lugar interrogador y fui hasta allí para transformar ese no lugar en un lugar donde podía observar y participar. Cuando le pregunté qué había pasado me contestó que los de la intendencia le habían dicho que cuando el contenedor estuviera en la calle donde hay mayor tránsito (depositado allí por los propios recolectores municipales) lo corriera y lo colocara donde siempre va, para no entorpecer la circulación de los vehículos. Ayudé a moverlo, y entretanto me contaba que no puede hacer mucha fuerza porque tiene problemas de arritmia. Mientras colocábamos el contendor en su sitio, llegó un joven a hurgar dentro de este. Nos saludó y comenzó a revisar las bolsas, «ropa, ando buscando ropa», contestó a mi pregunta de qué era lo que buscaba.

El espacio público (en este caso, la esquina), vivido en forma casual, se despliega en un juego de palabras, en la respuesta que informa, la charla con el desconocido que hurga y que nos muestra sus dificultades anónimas.

Otro vecino viene con varios cartones y los deposita dentro del contendor, aprovecha a comentarnos sobre el almuerzo que preparará. Cada uno de nosotros, mis vecinos, el joven hurgador y yo, nos integramos a través del contenedor de residuos a una sintaxis de interrelación y comunicación.

Intento así construir mi estrategia de investigación y empezar a comprender los nexos con el mundo de los residuos a través de la búsqueda de situaciones, de trabajar con informantes, de ser observadora y participante; constituir el camino para la búsqueda comprensiva del conocimiento en esos lugares híbridos.

Cuando salgo a la noche, observo a dos clasificadores en un carro tirado por un caballo, que llevan dos grandes bolsas de rafia de polipropileno blanca (plastillera). Se detienen en un contenedor. Revisan. Van seleccionando los cartones que encuentran, 
que depositan en el suelo; las botellas de plástico, que crujen lastimosamente al ser aplastadas con los pies; luego colocan los cartones y botellas en las enormes bolsas. Realizan la clasificación gruesa del material. Luego se marchan, y los veo detenerse a una cuadra a revisar otro contenedor.

\section{Actores}

A lo largo de la investigación pude identificar distintos tipos de actores participantes en el sistema de recolección de residuos:

- los vecinos del barrio;

- los hurgadores o clasificadores, invisibles a los ojos de los transeúntes, que muestran su agencia y su emergencia, a pie o en carros y alguno que otro motorizado;

- los recolectores, trabajadores cooperativos de una empresa contratada por la Intendencia del departamento;

- los comercios del barrio.

\section{EI contexto etnográfico}

El contexto etnográfico es el barrio Pueblo Nuevo, un espacio ideológico-simbólico y referente de identidades sociales, un espacio físico de la ciudad, que se materializa en la diferenciación de otros barrios de la ciudad. Pierre George define al barrio como

la unidad básica de la vida urbana (...) siempre que el habitante desea situarse en la ciudad, se refiere a su barrio (...) si pasa a otro barrio tiene la sensación de que rebasa un límite (...) sobre su base se desarrolla la vida pública (...). Por último-y no es el hecho menos importante- el barrio tiene un nombre, que le confiere personalidad en la ciudad. (George, 1977: 94)

Según datos históricos, hacia 1895, el fraccionamiento El recreo de Las Piedras (creado por Francisco Piria en 1874 y conocido como Pueblo Nuevo) fue anexado a la planta urbana de la ciudad de Las Piedras. Es un barrio integrado a la zona urbanizada debido al crecimiento de la ciudad, y está a doce cuadras del centro. Su población pertenece a la clase trabajadora mayormente, de nivel socioeconómico medio y medio bajo.

Desde tempranas horas hombres y mujeres se movilizan para el trabajo, poblando las paradas en espera de las líneas de transporte que los llevan a Montevideo (a $20 \mathrm{~km}$ de Las Piedras), en su mayoría. De ahí que todavía a la ciudad se la considere ciudad 
dormitorio o ciudad satélite, pues a partir de las seis de la tarde comienzan a regresar, cansados de la jornada laboral.

Las calles están pavimentadas, pero por las cunetas corren los efluentes domiciliarios formando un agua verdosa, debido a la falta de saneamiento. Los comercios reciben a sus clientes desde las siete u ocho de la mañana hasta las dos de la tarde, momento en que se toman un descanso; luego reabren sus puertas a partir de las cuatro y media de la tarde hasta las nueve de la noche. Las casas en su gran mayoría son de material, algunas de dos plantas, muchas enrejadas, otras con jardín y árboles en la vereda. También hay algunos edificios de apartamentos.

En las esquinas están los contenedores metálicos para residuos domiciliarios, maltratados por el mal manejo que de ellos hacen los recolectores de la intendencia, alguno que otro incendiado, muchas veces sobrecargados de residuos y comúnmente rodeados de restos que se descartan afuera de ellos.

Lo emblemático del barrio es el Molino de Bosch, conocido popularmente como el Molino Viejo, monumento fundamental para el paisaje y la arquitectura del barrio. Su función principal era triturar toda clase de cereales para hacer harinas y gofio. Joaquín Bosch, dueño de una fábrica de velas de sebo, mandó a construir el molino a principios del siglo XIX, época en la que el mercado de la harina crecía en nuestro país. En Canelones (nombre del departamento) llegaron a contarse 18 molinos de viento, señal de la agroproducción del departamento, que abastecía a Canelones y Montevideo. Fue un referente para los viajeros y una de las primeras actividades industriales de la zona. Este molino mantiene su forma original, aunque ya no presenta las aspas que lo caracterizaran. Es un punto de referencia para el barrio (Pedemonte, 1991). Los comercios que lo rodean toman su nombre, veterinaria El Molino, ferretería El Molino, y así, otros. Fue declarado monumento histórico en 2007. 


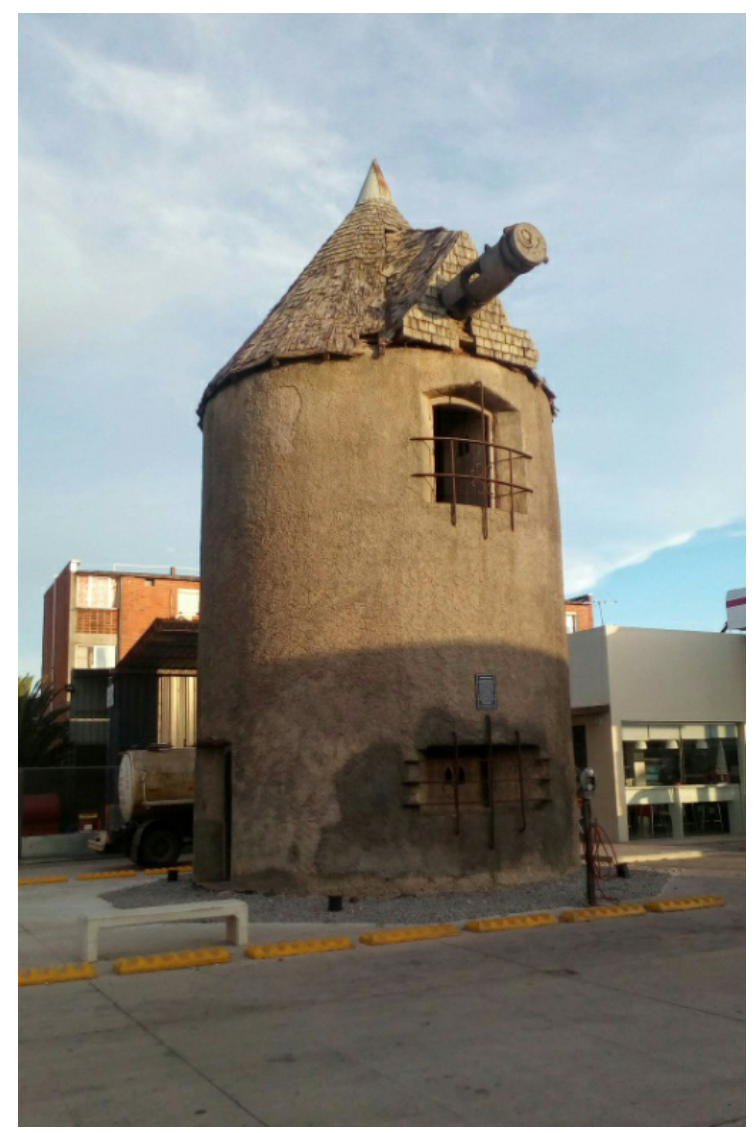

Molino de Bosch, construido entre 1859 y 1863. (Imagen propia)

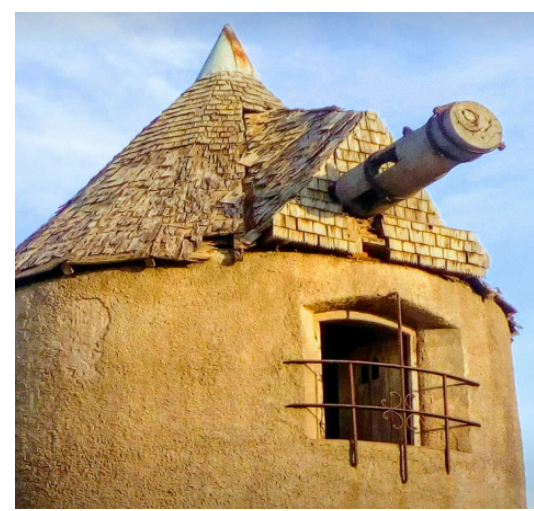

Molino de Bosch. Detalle de donde iban las aspas. (Imagen propia)

\section{Los residuos en la vida social}

Históricamente, la generación de desechos está asociada a la aparición misma de las sociedades humanas. En los diferentes momentos históricos, la producción de residuos ha surgido vinculada en forma directa a la relación de los sujetos con la reproducción material de esos residuos, que responde a las prácticas de consumo adoptadas, así como a las formas de adaptación al hábitat. Desde las primeras civilizaciones humanas se 
visualiza la existencia de desechos, caracterizados por ser las sobras de las prácticas alimenticias vinculadas principalmente a la supervivencia, a partir de los recursos naturales presentes en los territorios donde el hombre desplegaba su accionar.

La progresiva evolución de las capacidades humanas de producción, mediante la agricultura y la cría de animales, permitió una mayor autonomía en relación a los recursos existentes en el medio, a la vez que generó las condiciones para la radicación de los colectivos humanos en distintos territorios, permitiendo la sedentarización. Esto tuvo implicancias en la relación del hombre con los desechos, los cuales, a partir del abandono de la vida nómade, comienzan a cobrar presencia en las cercanías de los asentamientos. La creciente y elevada domesticación, modificación y transformación de la naturaleza, va acompañada de un desarrollo de la cultura material, lo cual conlleva al establecimiento de nuevas relaciones con los objetos y creaciones culturales, así como con los restos de dichas producciones, los que, al perder su valor y utilidad, adquieren el carácter de desecho (Teixeira, 2014).

En este proceso, los desechos adquieren significaciones que los anteponen y expulsan de las prácticas culturales, aproximándose a las connotaciones que en la actualidad atribuimos a ese objeto conocido como basura.

Para Bauman (2006) la producción de residuos y su eliminación se han convertido en un problema de primer orden en la agenda de la sociedad actual, que busca la forma más eficaz de invisibilizarlos, de destruirlos lo más rápidamente posible, con el fin de que no enturbien la consumista vida moderna y de eliminar, al mismo tiempo, su inquietante potencial conflictivo. Los residuos constituyen una consecuencia inevitable de la modernidad, de sus procesos económicos y de la búsqueda del orden. Para este autor, los términos producto y residuo son inseparables y complementarios, pues el residuo, lo que, una vez obtenido el producto, se considera desechable y deseable de eliminar, fue anteriormente imprescindible para la elaboración del producto. Por esta razón señala: «Los basureros son los héroes olvidados de la modernidad. Un día sí y otro también, vuelven a refrescar y a recalcar la frontera entre normalidad y patología, salud y enfermedad, lo deseable y lo repulsivo, lo aceptado y lo rechazado» (Bauman, 2006: 43).

Vivir en el presente implica producir basura. Los hábitos culturales de consumo están en permanente transformación y, por lo tanto, no nos percatamos del ritmo o velocidad con la cual nos deshacemos de lo que ya no nos sirve, ya no utilizamos o se 
ha vuelto pasado de moda. Los residuos generados por los grupos humanos siempre existieron, pero su presencia, en tanto problema ambiental, es un fenómeno reciente.

La basura, además, es una mercancía de segundo orden porque se traduce en ganancias económicas y porque antes de llamarse basura fue producida como objeto primario de consumo (Guzmán Chávez y Macías, 2012).

\section{EI reconocimiento social de los residuos}

Los residuos se hacen presentes en las sociedades modernas según aumenta el nivel de vida de la población. Existe una correlación entre nivel económico y cantidad de residuos que se producen: a mayor nivel económico, mayor cantidad de residuos. Si bien este no es el único factor que incide, es el más significativo.

El residuo es, ante todo, un hecho social, diferente según sociedades y épocas. Representa un valor cultural y social para los individuos que conforman la sociedad, por lo que la problemática de los residuos no es esencialmente técnica, sino que es básicamente social.

Las sociedades urbanas han producido, desde épocas muy antiguas, gran cantidad de residuos difíciles de reciclar o de recuperar. Con el desarrollo industrial, el desequilibrio natural del ser humano como productor y consumidor llega a su punto máximo en las sociedades actuales, netamente productoras de residuos e incapaces de reciclarlos y devolverlos al medio sin agredirlo.

El aumento de los sistemas de producción generadores de residuos, del consumo en general de materias primas, de la menor durabilidad de los productos, de la tendencia a la concentración de la población en núcleos urbanos, de la producción y consumo generalizados de envases sin retorno fabricados con materias no biodegradables, de los cambios en el estilo de vida, todos ellos son causas destacadas de la problemática de los residuos (Pardo, 1998).

Según Moore (2006) la basura y la suciedad son parte constitutiva del mercado comercial y de las prácticas de responsabilidad y consumo. Al mismo tiempo que la sociedad quiere ser limpia y ecológica se apoya en patrones de conductas que van creando más y más basura. Se vive en un doble proceso de modernidad, el de producir un ambiente imaginario de orden y limpieza y espacio racional, y al mismo tiempo se afirma la constante expansión del consumismo. Por tanto, en la modernidad, la producción de residuos excede la capacidad para expulsarlos y purificar el espacio de la ciudad. 


\section{Construcción de la imagen. Basura o residuo}

La diferenciación conceptual entre basura y residuo radica en la percepción que se tiene de los desechos materiales. El término basura tiene que ver con el sistema de manejo técnico y administrativo, con una percepción que la define como algo inservible, que no tiene mayor utilidad. Y que debe por tanto eliminarse. En cambio, cuando se habla de residuos sólidos se parte de una percepción integral, se consideran artículos que pueden separarse, clasificarse y almacenarse para luego aprovecharlos e integrarlos de nuevo a los ciclos productivos de la misma sociedad que los produjo (Bernache, 2006).

Mary Douglas (1973) plantea que el descubrimiento de la transmisión de las enfermedades por medio de las bacterias a finales del siglo XIX tuvo efectos tan profundos en la vida social que desde entonces se hace difícil pensar en la suciedad sin evocar su carácter patógeno. Sostiene, sin embargo, que nuestros comportamientos frente a la contaminación son anteriores a aquel momento histórico, de modo que no pueden explicarse a partir de él. Plantea, a su vez, la necesidad de separar nuestras ideas sobre la suciedad de lo patógeno y la higiene, para llegar a la definición: «la suciedad es materia fuera de lugar» (Douglas, 1973: 53), y por ello constituye una amenaza contra el orden. Desde esta perspectiva, no hay elementos que puedan ser considerados sucios por sus características intrínsecas (impureza, inutilidad, etcétera), sino que ocupan ese lugar como resultado de un proceso social e histórico de clasificación y separación.

El criterio de utilidad/inutilidad juega un papel fundamental como argumento sobre el que se apoya la demarcación que produce al desecho. Si tirar algo "a la basura" es, fundamentalmente, separar lo que todavía queremos conservar, de lo que consideramos inútil o simplemente ya no deseamos guardar, la forma en que se clasifica, es decir, en que se decide qué queda de un lado (basura/suciedad) y qué del otro (orden), refiere a una definición sociohistóricamente situada, además de ser una cuestión de clases sociales, de género y generacional (Strasser, 2000).

Continuando con Douglas, la autora dice que hay una etapa en que las cosas que fueron desechadas conservan todavía un resto de identidad: «se consideran como los fragmentos indeseables de la cosa de que proceden, pelo, comida o envoltorios» (Douglas, 1973: 55). Luego, a partir de un largo proceso de pulverización y podredumbre, terminan por perder cualquier rasgo identitario. Ese momento intermedio, en el que los desechos conservan lo que la autora llama una semi-identidad, es lo que 
constituye un peligro. Por ello, dice, «resulta desagradable hurgar en la basura en busca de algo perdido, pues esta acción reanima la identidad» (Douglas, 1973: 55). En cambio, cuando esa identidad se difumina por completo deja de ser peligrosa, puesto que pasa a pertenecer a un lugar definido, desprovisto de ambigüedad, «a un montón de basura de una u otra especie» (Douglas, 1973: 214).

La basura es una categoría compleja y dinámica, creada a través de un proceso clasificatorio donde se decide lo que se conserva y lo que se tira. La concepción de lo que se considera suciedad y desechos varía según la sociedad de que se trate. De este modo, no habría elementos útiles o inútiles por sí mismos, sino que su utilidad deviene de construcciones sociales que incansablemente realizan la delimitación entre lo aceptado y lo rechazado, lo deseable y lo repulsivo, el adentro y el afuera del mundo humano.

En un tiempo se consideró que la basura era materia temporalmente fuera de su lugar, de tal manera que, para reubicarla, la escoba era una herramienta suficientemente poderosa. Bajo el argumento del saneamiento de las ciudades, surgió el objetivo de alejarla y distanciarse de la basura. Es así como, en el siglo XIX, nace el concepto moderno de la higiene, y la basura, a través del servicio de limpieza, es sacada de las ciudades (Luna, 2003).

Con la llegada de diversos servicios a los ciudadanos también aparecen personas que trabajan en su desempeño, en este caso los recolectores o basureros, aunque esta acepción hace referencia tanto al lugar donde se amontona la basura, como a la persona cuyo oficio es recogerla (Parra, 1992). La dualidad limpieza/suciedad se usa para clasificar a lugares y personas. La basura también puede ser lo que se tira fuera de la vista o lo que se empuja al otro lado de la frontera enfatizando la importancia de la distancia. Hay todo un abanico de posibilidades por las cuales los objetos, en un momento dado, se convierten en basura, $\mathrm{y}$, al diversificarse, también se multiplican las maneras de clasificarla.

El concepto de residuo, es definido como lo que queda de un todo después de haber quitado una o más partes; es decir, el material que queda como inservible después de haber realizado algún trabajo u operación. Un residuo solo merece la connotación de suciedad cuando es arrojado y encerrado en el contenedor de la basura, hasta que sus condiciones físicas (como su olor o el amontonamiento) causan una impresión de 
impureza y de suciedad (Salgado, 2012). Los residuos adquieren su identidad cuando se les coloca en un recipiente de basura.

Ciertas categorías que permanecen subsumidas en términos tales como basura, desperdicio, desechos o residuos sólidos urbanos son resultado tributario de una concepción economicista del consumo, entendido como fase final del proceso de producción de mercancías a gran escala.

\section{La gestión de residuos}

Las distintas formas de percepción y gestión de los residuos se corresponden con una construcción histórica que cruza dimensiones sociales, políticas, económicas y simbólicas. La percepción de los residuos como un problema y su alejamiento a los márgenes de la ciudad surgen en el Uruguay en las últimas década del siglo XIX y principios del XX, asociados a la modernización capitalista del país y a la construcción de una nueva sensibilidad civilizada, la cual predicaba la higiene y la conservación de la salud, y rechazaba la suciedad y la enfermedad; lo que lentamente fue transformando la relación del hombre con el entorno urbano (Barrán, 1998).

Aparecen entones los primeros sistemas informales de tratamiento de residuos, que suponían su recolección y transporte a las periferias urbanas para ser quemados a cielo abierto (Elizalde et al., 2012).

La progresiva percepción de la basura como problema a atender hizo que empezaran a perfeccionarse los sistemas para gestionarla.

Desde mediados del siglo Xx, la consolidación del modelo industrializador produjo un aumento de la cantidad de residuos, junto con la aparición en forma masiva de materiales reciclables, como papel, cartón, envases de vidrio y metales. Se crean entonces las condiciones para la existencia de un mercado de los desechos, y con ello surgen los clasificadores, dedicados a la recolección, clasificación y venta de residuos (Fry, 2015).

En la última década de siglo XX se observa el surgimiento de un discurso ambiental vinculado a los residuos, promovido desde organismos internacionales. Para la década de los ochenta se comenzaba a tener una conciencia ambiental y el Informe Brundtland (1987), que dio a conocer el concepto de desarrollo sustentable, fue una de las primeras respuestas que implementaron planes y acciones para paliar el problema de los residuos, al ver que los tiraderos no eran una solución, como tampoco lo eran los incineradores surgidos al final del XIX. Es así como las sociedades industrializadas han desarrollado 
un sistema integral de gestión de residuos, formado por los siguientes elementos: reducción en origen, reciclaje, transformación de residuos y vertido (Alcaides, 2011). Adentrándonos en el siglo XXI, coexisten las tentativas de privatización de los servicios de recolección con las experiencias orientadas a desarrollar una gestión sustentable de los residuos. Sin embargo, estas últimas se implementan de forma parcial y fragmentada en distintos momentos del tiempo. Es así como se impone el sistema con contenedores (que permiten el almacenamiento de tres metros cúbicos de residuos), ubicados en permanencia en las calles de la ciudad y compartidos por varios vecinos. Estos acumulan los residuos en su interior, a la espera del camión recolector, con un joystick de control de carga lateral, conducido por un chofer y una segunda persona que ayuda en la operación de descarga. Ello se corresponde, actualmente, a lo que podemos llamar la parte visible del sistema de gestión de residuos urbanos domiciliarios. A los ojos de los ciudadanos, una flota de camiones se ocupa de la recolección oficial de los residuos.

\section{La entrada al campo}

La problemática que enfrenta el sistema de recolección de residuos en el barrio es que, luego de la instalación de contenedores públicos, el lugar que la basura ocupa en la vida de los ciudadanos cambió. Los habitantes se apropian de las esquinas para colocar desechos junto al contenedor, modificando el espacio, a la vez que lo contaminan, generando microbasurales entorno a estos.

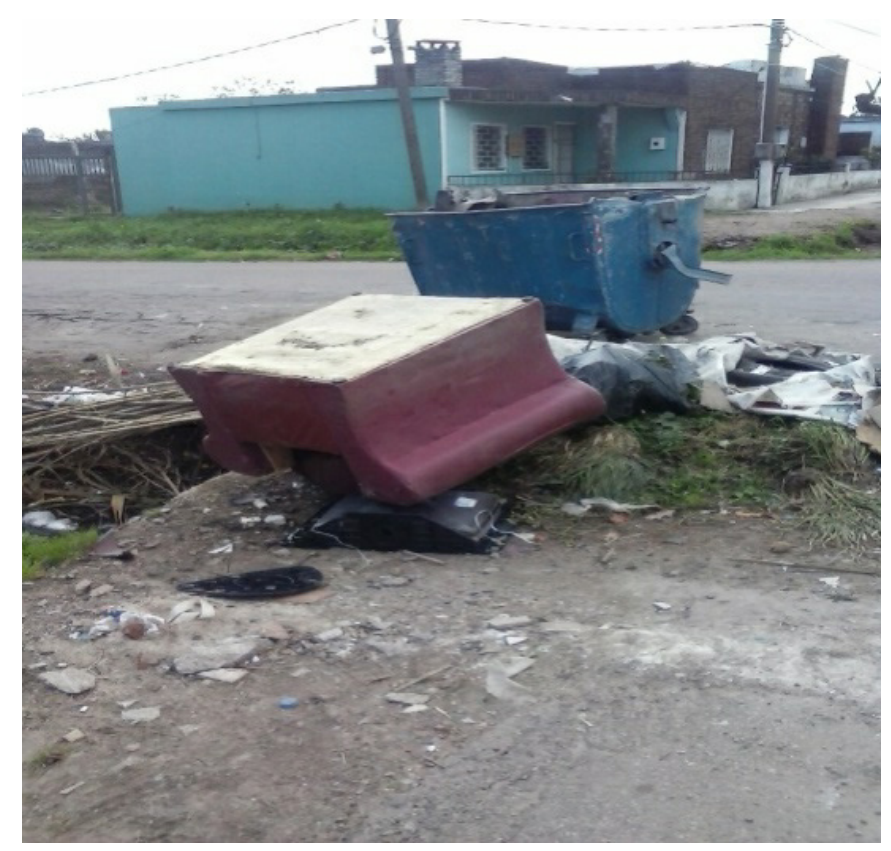

Restos de un televisor y un sillón al lado del contenedor, como guardianes esperando a que alguien los recupere. (Imagen propia) 
No debemos olvidar que la basura y la suciedad son parte constitutiva del mercado comercial y de las prácticas de consumo y responsabilidad individual.

Esta investigación etnográfica focalizó el problema en las prácticas que se refieren al sistema de recolección de residuos urbanos, y en la percepción que tienen los distintos actores frente a la basura, buscando entender el porqué de aquellas y lo que dejan entrever en el discurso, para interpretar y aportar conocimiento al entramado socio-simbólico-cultural que determinan unas y otras.

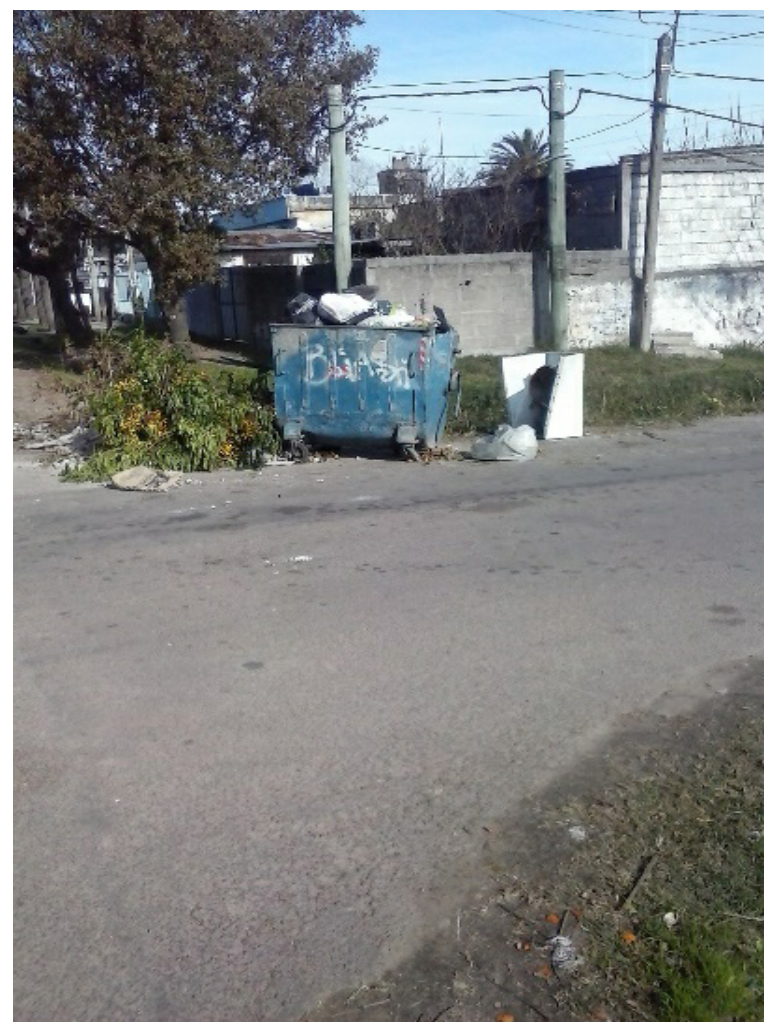

Contenedor lleno de residuos, con ramas de árboles, producto de una poda, y la estructura de un lavarropas completan el paisaje. (Imagen propia)

\section{El mundo de los residuos en el barrio Pueblo Nuevo}

Los residuos circulan en un complejo sistema cerrado, con sus propias relaciones económicas, sociales y políticas, en el cual interviene, en forma anónima, toda la población. También aparece como parte del paisaje, ya que implica reconocer su presencia constante como parte cotidiana de las escenografías y las vivencias diarias del barrio. En este caso se utiliza el concepto de paisaje desde la óptica de Tim Ingold que considera:

El paisaje ni es idéntico a la naturaleza, ni está en el lado de la humanidad contra la naturaleza. Como el dominio familiar de nuestro habitar, está con nosotros, no contra nosotros. Pero no es menos real por eso. Al vivir en él, forma parte de nosotros, tal como nosotros somos parte de él. (Ingold, 2000: 19) 
Se hace cada vez más presente en las esquinas y en las cunetas destinadas a los efluentes domiciliarios, que atraviesan prácticamente todo el barrio, sumando también su cuota de residuos y contaminación a las calles.

Pero también existe otra relación que los vecinos del barrio establecen con los residuos: los residuos como un recurso de subsistencia. Los residuos como comida y vestimenta y los residuos como un recurso para generar un ingreso económico.

Estos residuos que la sociedad desecha como basura son el recurso con el que algunos hombres y mujeres cuentan para comer y vestirse. Es el caso de los hurgadores.

Otros utilizan los residuos domiciliarios para insertarse, aunque sea de manera informal, en el mercado productivo, y así obtener una recompensación monetaria. Es el caso de los clasificadores. Es así como estos individuos posicionados desfavorablemente en la escala social urbana improvisan soluciones, en el marco de lo cotidiano de sus vidas.

Todos los habitantes del barrio necesitan diariamente del consumo o del uso de diversos artículos, en mayor o menor cantidad, según su participación en la producción o sus propios hábitos o necesidades; pero es un hecho que todos, absolutamente todos, consumen o utilizan algo diariamente. Esto origina la formación y acumulación de residuos, como restos de comida, envases, envolturas, papeles, cajas, botellas, etcétera, o bien de artículos que por su tiempo de uso dejan de resultar útiles o prácticos: ropa vieja, juguetes rotos, radios, llantas, muebles, colchones, alambres, etcétera. De esta acumulación sobredimensionada se desprende la necesidad de deshacerse de los residuos a como dé lugar, y muchas veces también en dónde sea.

De acuerdo a las observaciones realizadas, existen diferentes prácticas de tirar los residuos en el barrio: algunos vecinos los tiran por las noches en la esquina más cercana a sus casas, al lado del contenedor; otros los ponen en bolsas de plástico, que luego colocan dentro del contenedor; algunos simplemente van por la calle tirando todo lo que ya no les sirve: envoltorios de caramelos y pastillas, envases de refrescos, bolsas, colillas de cigarrillos, boletos de ómnibus, etcétera; como si por arte de magia, todos esos residuos fueran a desaparecer o a hacerse invisibles.

Os resíduos domésticos são os restos de nosso consumo. ¿O que fazemos da quilo que não consumimos? Nos livramos disso afastando do nosso espaço de vida... O resíduo se caracteriza pelo abandono (espacial) de uma coisa e, em razão disso, do direito de propriedade do qual ele era objeto. É um res nullius, uma coisa sem dono, com frequência definida pelo lugar que ocupa na lixeira, na rua ou no espaço público. (Debary, 2017: 29-30) 
Están también los que no son habitantes del barrio, pero igualmente llegan hasta él para engrosar esta acumulación, muchas veces pasando con su auto y arrojando la bolsa de residuos desde la ventanilla, sin importar si cae dentro o fuera del contenedor.

Por si fuera poco, por las noches perros y gatos hurgan en el contenedor buscando alimentarse, tratando de apoderarse de alguna bolsa que luego rompen y su contenido queda desparramado junto al contenedor o por las veredas.

Lo que más abunda fuera del contenedor son restos de poda, ramas de árboles, pasto, en una primera instancia. Luego a esto se le empiezan a sumar escombros por refacciones domiciliarias, maderas por muebles desarmados, botellas de vidrio, bolsas conteniendo residuos. De esta forma, en un espacio de diez o quince metros, se forma un microbasural producto de prácticas descontroladas de arrojo de residuos.

\section{Los vecinos y los residuos}

Si bien todo lo que compramos está destinado a convertirse, tarde o temprano, en residuos, el mayor problema reside en cómo nos deshacemos de ellos. Los vecinos son actores fundamentales en el inicio de la cadena de los residuos. Desde que entró en funcionamiento el sistema de recolección por contenedores, los vecinos pueden tirar sus residuos en cualquier momento del día sin tener que estar pendientes de la hora que pasa el recolector. Este sistema logró modificaciones en la conducta de los usuarios: si al sacar los residuos el contendor está lleno, se los deja al lado, en el suelo, nadie vuelve a su casa con la bolsa de residuos nuevamente para esperar a que el contenedor tenga espacio para depositarla allí. Por otra parte, los restos de podas, de jardinería o de limpieza de terrenos, chatarras, escombros y otros objetos se colocan al lado de los contenedores, y como no son residuos domiciliarios los camiones recolectores no los levantan, por lo que permanecen allí días y días.

Irma es ama de casa, pero a su vez realiza algunos trabajos de limpieza. Hace poco que vive en el barrio, antes vivía en una zona rural. Deposita sus residuos en el contenedor que está a unos quince metros de su casa. Me cuenta que siempre lo encuentra desordenado porque tiran pasto, ramas, escombros, botellas, y queda todo sucio alrededor. Explica que en los otros contenedores que ve camino a su trabajo, siempre a los costados hay basura. Argumenta que es porque la gente no pone cuidado, no está consciente de que tiran y tiran. Para ella, la Intendencia (gobierno municipal) tendría que ser la que sancionara, por ejemplo, poniendo cámaras. Dice que la 
educación tiene que ver, pero que es difícil enseñar a la gente, y más cuando ya es gente grande.

Omar es chofer retirado, antes manejaba camiones de la Intendencia. Para él, el problema de la basura pasa por la educación y la responsabilidad de lo que el individuo hace. Considera un error la tercerización en lo que respecta a la recolección de la basura, y piensa que el gobierno municipal se quiso sacar el problema de encima. El contenedor en el cual deposita sus residuos está ubicado en la esquina de su casa. Dice que siempre está lleno, y que hay quienes pasan en auto y tiran la bolsa desde la ventanilla. Hace poco, unos vecinos organizaron una limpieza barrial que anunciaron por parlante, y anduvieron con un camión juntando basura. Omar me cuenta que aprovechó esa ocasión y limpió la vereda de su casa. Insiste en la educación, la responsabilidad y la conciencia.

Álvaro es sanitario, trabaja de forma independiente en reparación de cañerías e instalación de baños y cocinas. Nació y se crio en el barrio, y tiene dos hijos veinteañeros. Un tema que ve preocupante es el referente a los pañales desechables que se depositan en los contenedores de residuos y que aparecen destrozados en la calle y en cunetas, por acción de los perros. Dice que la intendencia limpia, pero que enseguida vuelve a llenarse de basura. También, que los que clasifican a veces rompen las bolsas y dejan tirado.

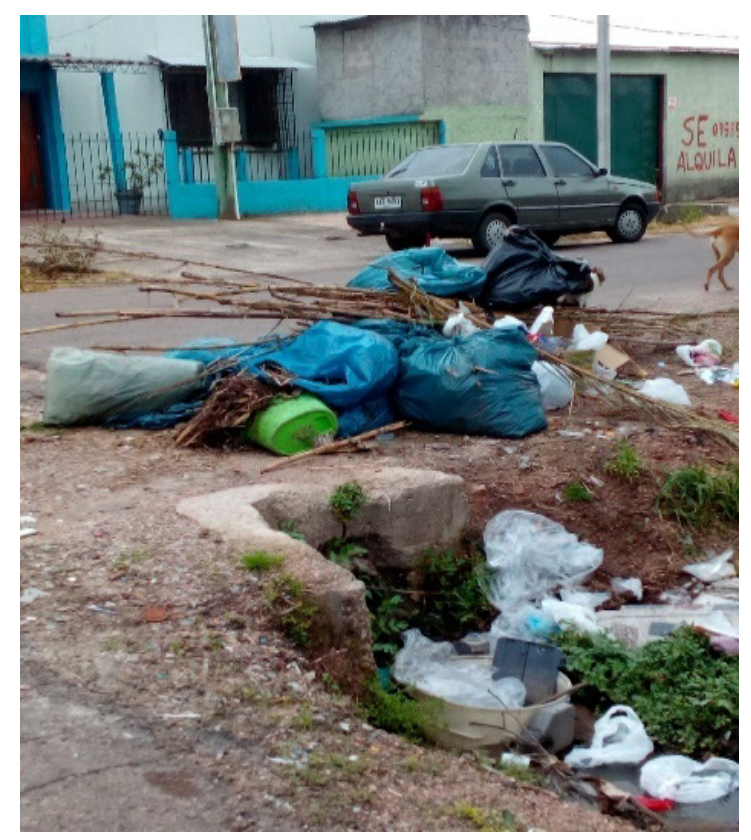

Las bolsas se acumulan en el microbasural. Otras han caído a la cuneta. La esquina invadida de lo que el consumo produce. (Imagen propia) 


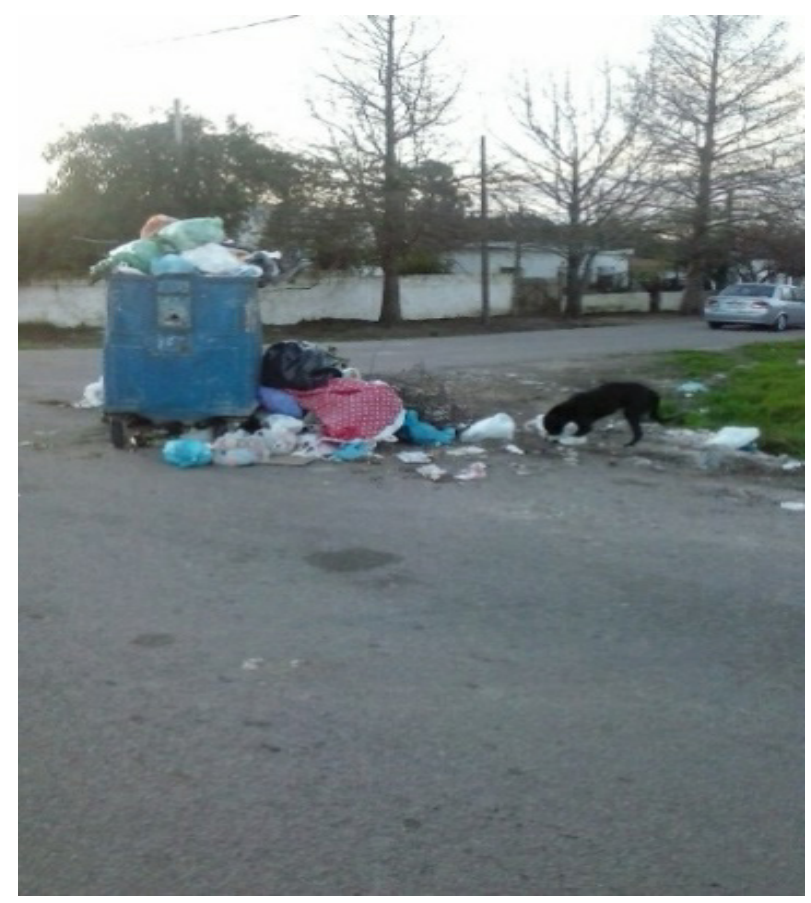

Perro hurgando en los alrededores del contenedor en busca alimento. (Imagen propia)

\section{Los clasificadores, recuperadores de residuos.}

La actividad de los clasificadores transcurre durante todo el día: de mañana, de tarde y durante las primeras horas de la noche. Van recorriendo el barrio (y luego, otros barrios) de distintas maneras, dependiendo de los medios o recursos a su alcance y las rutas de clientes que hayan construido. El medio de transporte que usan también está vinculado con la cantidad de residuos que pueden recolectar y las distancias que pueden recorrer. Desde carros tirados manualmente, carros tirados con bicicleta, alguno que otro con una moto, carros tirados con caballos hasta simplemente a pie, cargando las bolsas al hombro, realizan sus recorridos varias veces al día. La distancia, la duración del recorrido y la capacidad de recolección están relacionados con el medio de locomoción del que disponen. La organización de su trabajo es variada, aunque la mayoría trabaja de forma independiente. Recorren, seleccionan y clasifican el material. Luego lo llevan a un depósito o pueden acopiarlo en sus casas hasta que el intermediario pase a buscarlo. Es una población que comparte ciertas vulnerabilidades: bajos niveles educativos, la informalidad instalada en sus tareas y un alto índice de necesidades básicas insatisfechas, son algunos ejemplos. Pero un denominador común es que, cuando hablamos de clasificadores de residuos, los asociamos con basura y con desechos. Sin embargo, ellos son actores importantes en la gestión de residuos del barrio, pues contribuyen a reducir costos económicos y ambientales, y proponiéndoselo 
o no, llevan adelante una acción concreta en favor del medioambiente. «O resíduo é deixado à sua própria sorte e, em alguns casos, pode se tornar objeto de uma (re)apropriação pública, ocorrendo uma transferência de bensda quilo que constitui os restos» (Debary, 2017: 31).

El clasificador, sin saberlo y sin recibir compensación alguna por ello, es funcional a ese metabolismo social del capital (Quaroni, 2016).

Vivir de los residuos (y a veces hasta comer de ellos), implica pelear una batalla con la propia dignidad. Sin embargo, para los clasificadores, no tener o quedarse sin empleo no significa resignarse ni ser pasivos. Las actividades que dejan traslucir estos discursos manifiestan una cultura del trabajo. Caminar, recorrer, tomar el carro y transitar por el barrio en búsqueda de algo para recuperar es salir a trabajar. Vivir de lo que la sociedad descarta constituye para muchos la única actividad posible.

Luisa y Ana son dos vecinas que recorren los contenedores de los alrededores buscando objetos para vender en la feria. Salen a veces temprano en la noche. El problema laboral, la falta de empleo calificado, es el factor que desencadenó sus prácticas de recolección. Además, sus actividades también van engarzadas a la problemática de la pobreza y la exclusión social. Para ellas, lo que otros tiran se puede convertir en dinero para comer. Luisa dice que estuvo en el programa Barrido otoñal (un programa de la intendencia, que da trabajo a mujeres jefas de hogar) pero que ahora ya no. Tiene dos hijos de edad liceal. Con lo que vende, les compra los útiles a ellos. Ana, más reservada, va revolviendo y viendo qué sirve y qué no. Tampoco tiene empleo, y lo que encuentra, si es ropa, lo lava y lo vende en la feria. Hace bastante tiempo que vienen realizando esta tarea. Ambas declaran estar solas a cargo de los hijos, y su motivación está referida a este hecho. Las mujeres que salen a clasificar socialmente presentan la ausencia de una figura masculina en el hogar. Se observa diferencias de género en la elección de lo recuperado. Mientras Ana y Luisa llevaron una cartera, collares y ropa (que comercializarán en la feria vecinal), los clasificadores varones recuperaron cartón, papel, botellas, objetos con valor de reventa.

Pedro recoge cartones con su carro con bicicleta, antes lo hacía a pie. Ahora pudo comprarse un carro y le resulta mejor. Lo pagó él, declara. Trabaja muchas horas al día. Con lo que gana por los cartones que vende en el depósito mantiene a su familia. Hace años que trabaja clasificando cartones. Antes trabajaba en la construcción. Dice que en todos lados la gente tira al lado de los contenedores. El problema, afirma, son los 
pasteros (consumidores de pasta base), que son los que tiran más fuera del contenedor. Habla de la existencia de un código entre los clasificadores. Donde uno junta otro no puede juntar. Cada clasificador tiene sus espacios de recogida de material. La cadena económica de los papeles y cartones empieza con el descarte que realizamos en nuestro hogar, en los comercios y en las instituciones públicas y privadas. Los clasificadores cartoneros realizan la recuperación y clasificación en manera informal, invirtiendo, como en el caso de Pedro, en la compra de un medio de transporte, como lo es la bicicleta con la que tira del carro. El ciclo de recolección y clasificación de los materiales continúa con los intermediarios, y termina en las empresas de reciclado.

Las personas que se ven ante una situación de desocupación, subempleo, inestabilidad laboral, etcétera, buscan nuevas estrategias de sobrevivencia, entre ellas, la recolección y clasificación de residuos. En base empírica se puede visualizar una generación de plusvalía en la relación intermediario-clasificador. Lo que perciben los clasificadores por su tarea llega a ser muchas veces menos cuando lo venden al intermediario, y ni que decir con el valor del producto si es exportado. No obstante, se sienten bien o conformes con la tarea de recolección. Sin embargo, la posibilidad de cambiar de empleo está siempre latente, como forma de superar la situación de precarización de la actividad.

Sin seguros sociales ni aportes ni cobertura en salud, trabajan largas horas para ganar algo de dinero y llevarlo a su hogar. Ellos son el eslabón débil de esta cadena. Desde que comencé a trabajar en esta etnografía mi atención en los clasificadores fue en aumento. Hasta ese momento no había reparado en ello. Ahora, toda vez que salgo, ya sea aquí o allá, cada vez veo más gente en la vuelta revolviendo contenedores.

\section{Recolectar y vender en la feria. Viviendo de lo que otros tiran}

Por frente a mi casa todos los días pasa Horacio, pulcramente vestido, con su carro manual. Y los días de feria, lo encuentro instalado en una esquina, donde expone sus mercancías a la venta. Los clasificadores como Horacio rescatan objetos en desuso, que se arrojan a un contenedor o que se dan voluntariamente, para agregarles valor y luego comercializarlos en la feria del barrio. En uno de esos días que fui a la feria, decidí conversar con él para que me contara acerca su práctica de recolección. Tiene 62 años, ha acumulado cerca de veinticinco años de trabajo, entre ellos, doce años en la Intendencia de Maldonado y ocho años como militar. También trabajó en quintas y en 
granjas, pero aún le faltan cinco años para obtener una jubilación. A pesar de sus problemas de columna (osteoporosis, aclara, que lo tiene documentado por médicos), considera que no hay motivo para que lo jubilen por enfermedad. Hace dos años que vive en el barrio. Vino de Montevideo. Allí perdió su casa, lo robaron y decidió con su familia venirse para Las Piedras. Su familia la integran su esposa y un hijastro. Lo que tiran otros es una ayuda para la gente que no tiene trabajo, explica, lo que no les sirve a otros les sirve a ellos para hacer feria. Lo juntan, lo lavan, lo arreglan un poco, lo acondicionan y hacen feria. Junta metales, latón, bronce, plomo. Los fines de semana junta unos pesos con los metales que vende, eso le da para sobrevivir. Forzado a ser clasificador para subsistir, Horacio vive su vida, pudiera considerarse resignada y optimista, sin reparar que es producto de un sistema económico que no lo integra.

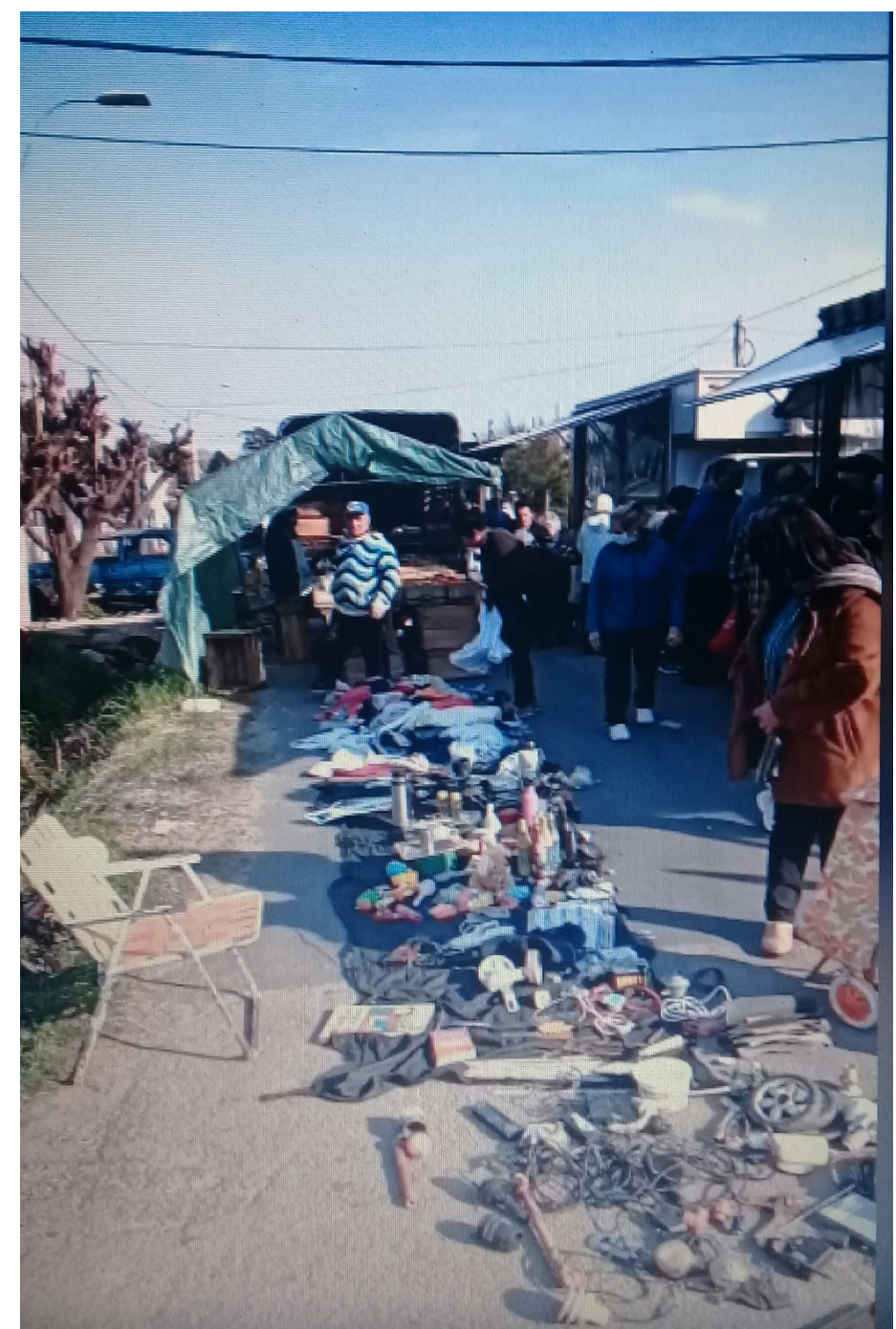

Los artículos recuperados se depositan en el suelo esperando al comprador interesado. Juguetes, libros, ropa, partes de objetos, todo sirve, todo tiene valor nuevamente y vuelve a circular. (Imagen propia) 
Usa un gancho para no meter la mano dentro del contenedor, así recolecta de él. Saca lo que le sirve, después lo otro lo deja adentro, bien ordenado, tratando de no tirar nada en el piso, porque siempre hay gente mirando. No usa guantes. Los residuos en los contenedores tienen materiales peligrosos, como vidrios, envases de enlatados, metales, jeringas, que pueden ocasionar heridas. Ya se he cortado en otra ocasión, y me muestra la palma de su mano con una cicatriz que cruza de un lado a otro. Son las marcas de los puntos. Fue hace como cinco años, tuvo que ir a la emergencia del hospital por la herida producida. Estuvo como un mes con la mano vendada, pero igual salía a recolectar. La clasificación es una estrategia laboral; implica largas jornadas laborales, esfuerzo físico, exponerse a accidentes, sin seguro de salud y también vivenciar la discriminación de la sociedad. Hay gente que discrimina, dice Horacio. Le han dicho: ¡Bichicome! ¡Andás revolviendo la basura! ¡Andá a trabajar! A veces, les ha explicado a esas personas que lo insultan: «si usted tuviera la edad que yo tengo, y no tuviera trabajo, tendría que hacer esto».

Recorriendo las calles, el cuerpo emerge como la principal herramienta, al tirar del carro vacío cuando se sale y cargado cuando se regresa. La fuerza física acompaña ese caminar durante varias horas y va dejando huellas en los cuerpos; es el ritual diario que se vive como sacrificio. Acto de entrega, de sobrevivencia, expropiando la energía corporal, para devolver a la rueda del consumo objetos que habían pedido su valor de uso y de cambio.

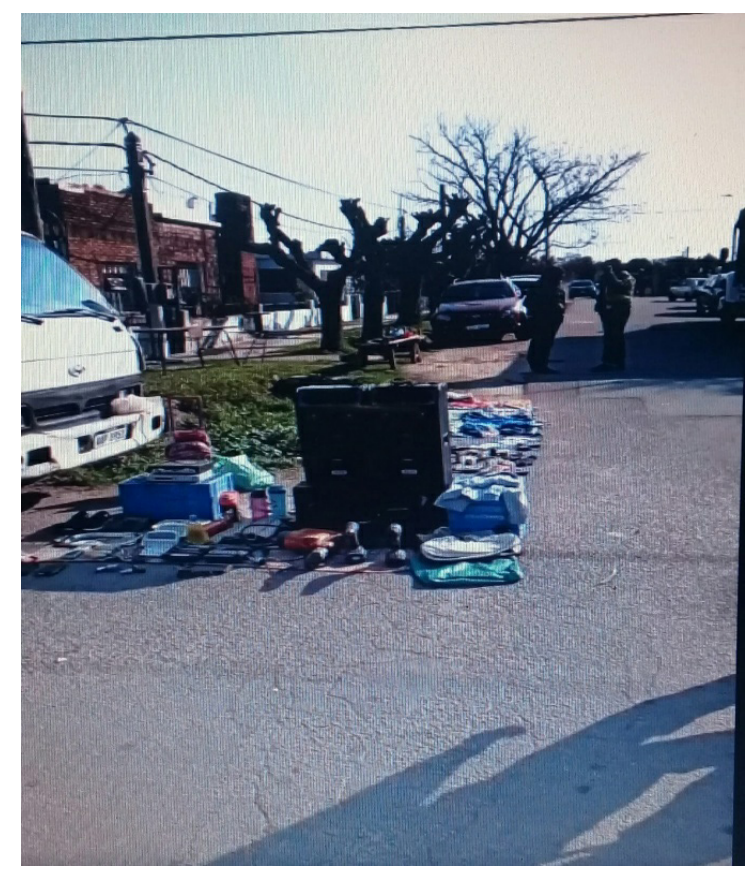

En varias cuadras se repite la imagen, vivir de lo que otros desechan. (Imagen propia) 


\section{Los comercios del barrio. Su relación con los residuos}

El espacio comercial es un elemento de la convivencia barrial, de sociabilidad y de acceso al consumo. Consumo que generará residuos para desechar. Una recorrida por el barrio muestra una variedad de comercios de distintos rubros. Almacenes, ferreterías, pizzerías, carnicerías, puestos de verduras, veterinarias, estación de servicio, bares y los supermercados, productos de la globalización, en el espacio barrial. Los residuos son una problemática que afecta también a los comercios por el volumen que se acumula a lo largo del día. Como generadores de residuos, estos comercios son un eslabón más de la cadena, y el acceder a sus discursos sobre el tema resulta inevitable. Dependiendo del comercio es posible identificar los residuos generados.

Hay residuos de empaquetado, como cartones, bolsas plásticas, envoltorios, flejes, madera. También se destacan los residuos de productos que comprenden devoluciones por cuestiones de calidad, vencimiento, promociones concluidas, y productos con envases rotos, caídos, etcétera. Los productos que el comercio compra al proveedor son ubicados en estantes, vitrinas, góndolas o cajones. A través de la venta, su empaque y entrega, llegan al cliente. Hay productos que llegan en un envase mayor, que suele llamarse envase secundario. Este último se transforma en residuo cuando los productos son colocados a la venta. Existe una disposición que establece que los comercios no pueden disponer sus residuos en el sistema de contenedores, sino que deben contratar un servicio especial para su retiro y transporte. La intermediación en la cadena económica reincorpora al circuito industrial estos residuos de los comercios para su posterior valorización.

La persona que va a recoger el excedente de cartón, nylon, etcétera, es un recuperador informal que construye un negocio en torno a esto. Esta informalidad es un elemento constitutivo del negocio de los residuos. Deja librado a la responsabilidad del recuperador el hacer una correcta gestión de los residuos para que no se conviertan en contaminación ambiental. 


\section{Conclusiones}

En el barrio Pueblo Nuevo, los contenedores se encuentran repletos de residuos que se derraman hacia la calle y a su alrededor, desechos del consumo que se depositaron anónimamente invadiendo el espacio. ¿Y esto por qué?, porque nosotros, los vecinos del barrio, tiramos la basura de cualquier manera y en cualquier sitio. La teoría de las ventanas rotas o los vidrios rotos establece una conexión de un estado de abandono, de ausencia de control y normas, donde impera el anonimato (como puede ser un contendor público) con una actuación irresponsable. Esto puede transformarnos en víctimas potenciales del descontrol que genera esa sensación de que todo es posible porque a nadie le importa, nadie controla, nadie sanciona, nadie nos ve. «O vazio social se expressa através de um conjunto de sinais de abandono e de atitudes de rejeição aos resíduo» (Lesbet, 1999 citado en Debary, 2017: 30). El problema de los residuos se objetiva desde distintas miradas. Sirve como herramienta de construcción desde fuera, refleja cómo nos relacionamos con los residuos en el barrio y cómo es interpretado desde su lugar. Si bien todos los habitantes de Pueblo Nuevo tenemos derecho al barrio, se debe entender, desde la idea, que el barrio es una obra, un producto social del cual los vecinos somos protagonistas, y que debemos instaurar la posibilidad de relacionarnos desde una nueva perspectiva con nuestros residuos, asumiendo responsabilidades.

La mala disposición de los residuos junto a los contenedores públicos repercute en forma negativa en el barrio en su conjunto. La contaminación del entorno se hace presente y no nos hacemos protagonistas de ello. El desentendimiento hacia los residuos que generamos, una vez que estos abandonan nuestra vivienda, es visible. Sentimos que los residuos quedan fuera de nuestra responsabilidad, que el servicio de limpieza tiene que hacerse cargo. Formamos basurales y los volvemos invisibles a nuestra mirada; los vemos, pero no nos llaman la atención.

La preocupación que guió esta etnografía fue la de conocer las prácticas que determinaban la apropiación de los espacios públicos de los contenedores y su entorno para arrojar basura, y conocer qué percepciones tenían de ellas quienes forman parte del circuito de los residuos. Se puede comprender el abordaje de la problemática de la basura desde lo conductual y desde la gestión. La participación de los vecinos es fundamental, y es necesario un diseño participativo que involucre a todos los ciudadanos en la gestión de sus residuos. Me atrevo a decir que la educación ambiental se hace necesaria para todos, porque todos generamos residuos. Además, las estrategias 
de comunicación deben ser variadas para abarcar a la todos los integrantes de este circuito, en una responsabilidad compartida, con el fin de lograr un cambio de hábitos en lo cotidiano. La valorización del espacio público en el barrio es clave en todo esto, ya que es un espacio compartido, un orden social. Las interacciones y la coexistencia, con sus restricciones y permisos, implican normas de comportamiento que determinan un orden público que debe mantenerse para lograr una convivencia adecuada y tolerante. Las disrupciones de actuación (Goffman, 1989) en cuanto al arrojo de basura crean molestias, desconcierto, intolerancia entre los vecinos, desorganizando el sistema social del barrio y el espacio público, lugar de interacción social. Es imperioso crear conciencia ambiental para que no naufraguemos en un mar de basura.

Un tema importante es el de los clasificadores. La sociedad invisibiliza el esfuerzo de ellos como valor ambiental relevante, el cual, lejos de ser reconocido, es mirado con estigma por una parte de ella. Como antes había señalado, ciertas formas de exclusión social relacionada con bajos ingresos en el hogar, con necesidades básicas insatisfechas, con bajo nivel educativo, condicionan a buscar estrategias de supervivencia familiar a partir de la cadena de la basura. Los clasificadores, además de contribuir con el medioambiente, encuentran el sustento familiar y ponen en marcha una cadena de recuperación de materiales, reinventando la mercancía y el trabajo, allí donde antes había residuos y desempleo. Es oportuno recordar que los clasificadores han aparecido debido a cambios en la matriz productiva que generaron desempleo, a la vez que la cantidad de residuos con valor de cambio les permitieron sobrevivir, a partir de su recolección.

Culminando el trabajo etnográfico, el barrio se apronta para un cambio en la recolección de residuos a través de contenedores domiciliarios que han empezado entregarse a los hogares y de la supresión de los contenedores públicos que han sido retirados de las esquinas. Esto ha sido una iniciativa de la gestión ambiental de la Intendencia de Canelones. 


\section{REFERENCIAS}

AlCAIDES, Ángeles. Residuos sólidos urbanos. Una consecuencia de la vida. Universitat Jaume, 2001.

Disponible en: https://www.yumpu.com/es/embed/view/o0PTtUBqXhQHkkg6

BARrÁn, José Pedro. Historia de la sensibilidad en el Uruguay. Tomo II: El Disciplinamiento (1860-1920). Montevideo, Ediciones de la Banda Oriental, 1998.

Bauman, Zygmunt. Modernidad y ambivalencia. En: Giddens, Anthony; Bauman, Zygmunt; LuHMANN, Nicklas y BECK, Ulrich. Las consecuencias perversas de la modernidad: modernidad, contingencia y riesgo. Barcelona, Anthropos, 2006. p. 73.

Berger, Peter y Luckmann, Thomas. La construcción social de la realidad. Buenos Aires, Amorrortu, 2001.

BERNACHE, Gerardo. Cuando la basura nos alcance: el impacto de la degradación ambiental. México, Centro de Investigaciones y Estudios Superiores en Antropología Social, 2006.

GuzMÁn ChÁvez, Mauricio y Macías, Carmen. El manejo de los residuos sólidos municipales: un enfoque antropológico. El caso de San Luis Potosí, México. Estudios Sociales. Revista de Alimentación Contemporánea y Desarrollo Regional, Hermosillo (Sonora), 2012, vol. 20, n. 39, p. 235-262, 2012. Disponible en: www.ciad.mx

Debary, Octave. Antropología dos restos: da lixeira ou museu. Pelotas, UM2Comunicaçao, 2017.

Douglas, Mary. Pureza y peligro. Un análisis de los conceptos de contaminación y tabú. Buenos Aires, Siglo XXI Editores, 1973.

ElizALde, Lucía; Fry, Mariana; Musto, Leticia; SAnguinetTi, Martín; SARAChU, Gerardo y TEXEIRA, Fernando. Clasificadores/as de residuos urbanos sólidos en Montevideo: condicionamientos, posibilidades y tentativas de organización. Revista Contrapunto, n. 1, Luchas sociales y gobiernos progresistas en América Latina, p. 63-91, dic.2012. Disponible en: www.extension.udelar.edu.uy 
FRY, Mariana. Clasificadores de residuos sólidos urbanos: un análisis desde el campo de recuperación de desechos y las diversas formas de sujeción del trabajo que produce. Tesis (Maestría en Sociología). Facultad de Ciencias Sociales. Universidad de la República, Uruguay. Montevideo, 2015. Disponible en: www.colibri.udelar.edu.uy

GEORge, Pierre. Geografía urbana. Barcelona, Ariel, 1977.

GOFFMAN, Erving. La presentación de la persona en la vida cotidiana. Buenos Aires, Amorrortu, 1989.

INGOLD, Tim. The perception of the environment: Essay on livelihood, dwelling and skill. Londres, Routledge, 2000.

LuNA, Gabriela. Factores involucrados en el manejo de la basura doméstica por parte del ciudadano Tesis (Doctorado en Psicología Social). Departamento de Psicología Social, Universidad de Barcelona, 2003. Disponible en: www.tdx.cat

MoORE, Sarah. (2006) The politics of garbage: municipal solidwaste in Oaxaca, México. Master's Theses, University of Kentucky. Disponible en: www.uknowledge.uky.edu

PARDO, Mercedes. Sociología y medioambiente: estado de la cuestión. Revista Internacional de Sociología, n. 19-20, p. 329-367, 1998.

Disponible en: $\underline{w w w . s o c i o l o g i c o . c o m}$

PArra, Pablo. (1992). Diccionario enciclopédico Planeta Agostini. Barcelona, Planeta, 1992.

Pedemonte, Juan Carlos. Los Viejos Molinos de Viento. Sugestivas siluetas desaparecidas en nuestro horizonte. Almanaque del Banco de Seguros del Estado 1991, p. 86-91, 1991.

QUARONI, Antonio. El hombre y sus derivas: por una vida digna en un marco de sustentabilidad. Trabajo final de grado (Licenciatura en Psicología), Facultad de Psicología, Universidad de la República, Uruguay. Montevideo, 2016.

Disponible en: www.biur.edu.uy 
SAlgADO, Juana Amalia. Residuos sólidos: percepción y factores que facilitan su separación en el hogar. El caso de estudio de dos unidades habitacionales de Tlalpan. Quivera, Revista de Estudios Territoriales, vol. 14, n. 2, p. 91-112, jul-dic, 2012. Disponible en: www.redalyc.org

STRASSER, Susan. Waste and want: a social history of trash. New York, Owl books, 2000.

VELASCO, Honorio y DíAz de RADA, Ángel. La lógica de la investigación etnográfica. Un modelo de trabajo para etnógrafos de escuela. Madrid, Editorial Trotta, 2006.

Velho, Gilberto. Observando o familiar. En: Velho, Gilberto, Individualismo e cultura: notas para uma antropologia da sociedade contemporânea. Rio de Janeiro, Zahar Editores, 2004. p. 123-132.

TYLER, Stephen. Etnografía postmoderna: Desde el documento de lo oculto al oculto documento. En: Clifford, James y Marcus, George (Eds.). Retóricas de la antropología. Madrid, Ediciones Júcar, 1991. p. 183-204.

Recebido: $28 / 08 / 2020$

Aprovado: $08 / 12 / 2020$ 